
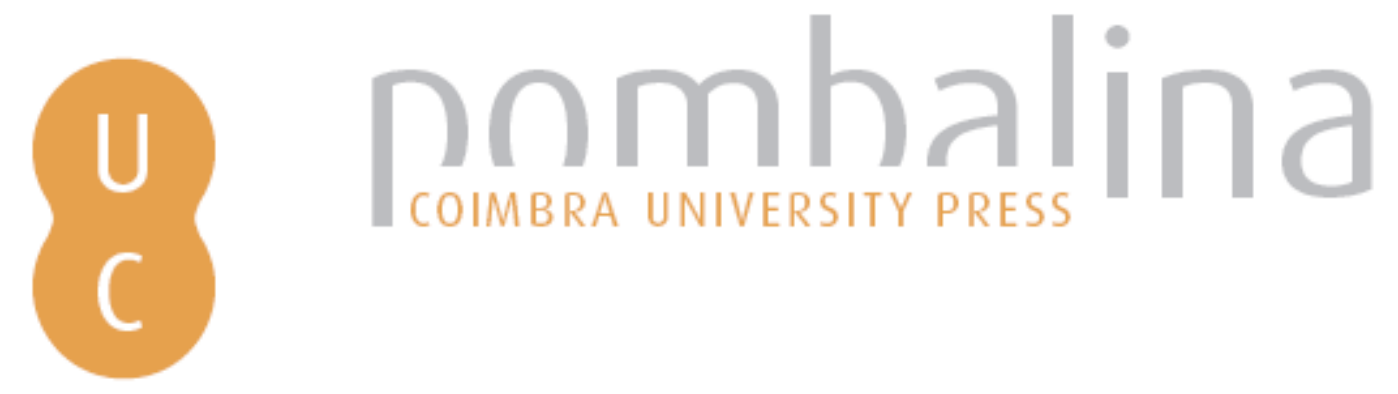

\title{
Sabedoria e educação: um estudo com adultos da Universidade Sénior
}

Autor(es): $\quad$ Gonçalves, Cidália Domingues; Oliveira, Albertina Lima de

Publicado por: Imprensa da Universidade de Coimbra

URL

persistente:

URI:http://hdl.handle.net/10316.2/31289

DOI:

DOI:http://dx.doi.org/10.14195/978-989-26-0228-8_21

Accessed : $\quad$ 26-Apr-2023 14:23:01

A navegação consulta e descarregamento dos títulos inseridos nas Bibliotecas Digitais UC Digitalis, UC Pombalina e UC Impactum, pressupõem a aceitação plena e sem reservas dos Termos e Condições de Uso destas Bibliotecas Digitais, disponíveis em https://digitalis.uc.pt/pt-pt/termos.

Conforme exposto nos referidos Termos e Condições de Uso, o descarregamento de títulos de acesso restrito requer uma licença válida de autorização devendo o utilizador aceder ao(s) documento(s) a partir de um endereço de IP da instituição detentora da supramencionada licença.

Ao utilizador é apenas permitido o descarregamento para uso pessoal, pelo que o emprego do(s) título(s) descarregado(s) para outro fim, designadamente comercial, carece de autorização do respetivo autor ou editor da obra.

Na medida em que todas as obras da UC Digitalis se encontram protegidas pelo Código do Direito de Autor e Direitos Conexos e demais legislação aplicável, toda a cópia, parcial ou total, deste documento, nos casos em que é legalmente admitida, deverá conter ou fazer-se acompanhar por este aviso. 


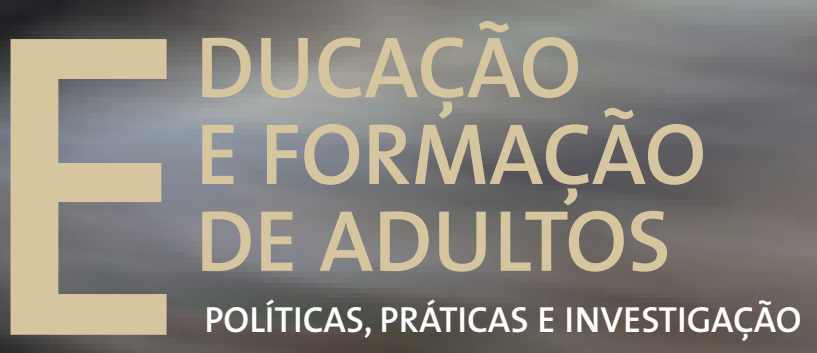

Luís Alcoforado • Joaquim Armando G. Ferreira António Gomes Ferreira • Margarida Pedroso de Lima Cristina Vieira • Albertina L. Oliveira • Sónia Mairos Ferreira 


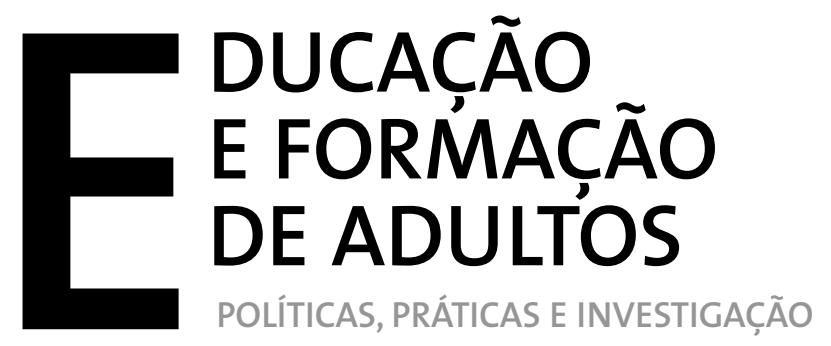

Luís Alcoforado • Joaquim Armando G. Ferreira António Gomes Ferreira - Margarida Pedroso de Lima Cristina Vieira • Albertina L. Oliveira • Sónia Mairos Ferreira 
EDIÇÃo

Imprensa da Universidade de Coimbra

URL: http://www.uc.pt/imprensa_uc

Vendas online: http://www.livrariadaimprensa.com

CONCEPÇÃO GRÁFICA

António Barros

Pré-Impressáo

SerSilito-Empresa Gráfica, Lda

EXECUÇÃo GRÁFICA

SerSilito-Empresa Gráfica, Lda

ISBN

978-989-26-0136-6

DePósito LEgaL

$340309 / 12$ 



\section{SABedoria E EdUCAÇÁo: UM ESTUDO COM ADULTOS DA UNIVERSIDADE SÉNIOR}

Cidália Domingues Gonçalves

Albertina Lima de Oliveira

Universidade de Coimbra

\section{Introduçáo}

Pensamos que investigar em Educação é uma forma de contribuir não só para se obter mais e melhor conhecimento neste domínio e para se melhorarem as práticas educativas, mas consideramos, igualmente, tal como muitos outros autores (e.g., Simóes, 2007; Simóes et al., 2009; Amado, 2009), que é uma excelente forma de participar no aperfeiçoamento do ser humano. E foi esse o espírito que norteou a investigação, que agora apresentamos, através da qual pretendemos contribuir para uma melhor caracterização da idade adulta avançada, e para um melhor entendimento dos factores da história de vida mais susceptíveis de potenciar a sabedoria e o envolvimento activo em actividades de educação não formal. Se o passar dos anos nos torna, do ponto de vista biológico, mais velhos, o desafio pleno é tornarmo-nos melhores pessoas, mais humanos, mais conscientes de nós e dos outros, e pensamos que esse é igualmente um desafio para a investigaçáo educacional.

É consensual que a Educação de Adultos visa o aumento da autonomia e da reflexividade dos adultos (Simóes, 1979; Mezirow, 1991, 2000; Brookfield, 1995; Oliveira, 2007), mas estes objectivos não podem ser desligados de um desenvolvimento paralelo da sabedoria (Loevinger, 1987; Oliveira, 2002). E, nesse sentido, os educadores de adultos devem assumir a responsabilidade pelo desenvolvimento e a manutençáo de ambientes que promovam a sabedoria, daí ser tão importante a investigação desta problemática.

\section{Envelhecimento}

A sabedoria tem sido associada à idade avançada, sendo caracterizada como um ganho decorrente da idade, nomeadamente no contexto da perspectiva life-span. No entanto, essa relação não parece estar totalmente esclarecida. Entre a perspectiva comummente aceite de que a idade traz sabedoria e os resultados das investigaçóes empíricas, há grandes diferenças, muitas inconsistências e persistem questóes em aberto. Mas, detenhamo-nos, por agora, no conceito de envelhecimento.

O termo envelhecimento é-nos bastante familiar. Porém, a sua definição não é simples nem linear, tratando-se mesmo de um fenómeno que é encarado de forma diferente, consoante as sociedades, épocas históricas e as perspectivas teóricas ou científicas que subjazem à sua leitura. Podemos dizer que o envelhecimento é um processo multifacetado e complexo e, simultaneamente, universal, lento e gradual. Em geral, é associado à passagem dos anos, mas sabe-se hoje que a idade cronológica é apenas um dos critérios a ter em consideração. Estabelecer que, a partir dos sessenta e cinco anos de idade, se é idoso e deixa de se estar apto a trabalhar é uma convenção social, surgida num contexto específico. 
A velhice constitui assim um conceito histórico e culturalmente construído e, nessa medida, é uma "ficção social" (Gonçalves, 2010, p. 27). Neste sentido, Simóes (1990) refere que "o idoso simplesmente náo existe" (p. 109), o que reforça não só a ideia da construção social do termo, como a própria heterogeneidade do grupo a que chamamos idosos. Segundo o mesmo autor, sendo o envelhecimento um processo complexo, é possível ser-se "velho fisicamente, psicologicamente de meia-idade e jovem socialmente. Ou uma combinação diferente destas três situaçóes" (p. 110).

Para além de ser uma experiência individual, o envelhecimento é, igualmente, um fenómeno populacional dos mais marcantes (Simões, 2006). Estando a população idosa a crescer exponencialmente em todo o mundo, um importante desafio que se coloca à Educação de Adultos e, mais precisamente, à Gerontologia Educativa é compreender "o que significa, na realidade, ser velho em pleno século XXI? Ter mais de sessenta e cinco anos?" (Nazareth, 2009, p. 174). O autor critica aquilo que denomina de "produção de velhos" e antevê que a abordagem da problemática dos idosos passe pela extinção do próprio conceito de terceira idade, enquadrada numa perspectiva de contestação da visão negativa, ainda prevalecente, acerca do envelhecimento e, paralelamente, pelo acentuar das enormes potencialidades das pessoas mais velhas.

O fenómeno constitui-se, assim, como convocador dos educadores de adultos, na medida em que, como afirma Simóes (2006), as novas geraçóes de idosos são "mais saudáveis, mais longevas, mais instruídas" (p. 13). Neste sentido, segundo o mesmo autor, é de esperar que a procura de educação, por parte deste segmento etário, se intensifique, tornando-se os idosos "um novo público a educar", reforçando e dando verdadeiro sentido à ideia de uma educação permanente, que acompanhe todo o curso de vida.

\section{Educaçáo}

O conceito de educação, no seu sentido mais essencial, reveste-se de uma forte componente ética e moral, a qual lhe é constitutiva, estando, precisamente, relacionado com o desenvolvimento do ser humano, no sentido de cada um de nós se tornar melhor pessoa. Segundo Simões (2007), "educação é agir moralmente" (p. 15) e, por conseguinte, "educarse é tornar-se humano, ou melhor, é tornar-se mais humano" (p. 34). Perspectivando o conceito a partir da sua relação com a aprendizagem, o mesmo autor refere que "educar é aprender a ser", ou melhor, "educar é aprender a ser melhor" (1989, p. 6). Assim sendo, educação e aprendizagem, estando semanticamente relacionados, não são sinónimos. A aprendizagem visa a adaptação a situaçôes novas, inéditas, imprevisíveis, potenciando a capacidade adaptativa a situaçóes futuras e pode ser definida como uma mudança mais ou menos permanente da conduta. Ainda que no caso humano, a aprendizagem se revista de uma complexidade própria, não é uma resposta inteiramente nossa, ao contrário da educação, essa sim especificamente humana, a qual assenta na característica de educabilidade.

Esta visão educativa aponta para a concepçáo do ser humano como estando permanentemente inacabado, sendo capaz de se tornar, pela educação, livre, moral e autónomo: "seres condicionados mas não determinados", como muito bem acentua Freire (2008, p. 19). Nesta jornada de conquista de liberdade, e nas palavras de Freire, "gosto de ser gente porque, inacabado, sei que sou um ser condicionado mas, consciente do inacabamento, sei que posso ir mais além dele" (2008, p. 53). É, precisamente, esta consciência 
de estarmos em permanente processo de devir que é essencial para que o ser humano se eduque, porque só a partir dela se desenvolve a noção de que é possível mudar, melhorar e progredir. É também fundamentalmente esta condição que sustenta a necessidade da educação se estender a toda a duração da vida.

Ora, nos últimos anos, as políticas públicas têm vindo a defender o paradigma da Aprendizagem ao Longo da Vida, designação que surge nos discursos políticos como um forte desafio e que se tem vindo a afirmar quer em Portugal quer na Europa. Ela não é, contudo, inteiramente nova. Trata-se de uma expressão que surge nas décadas de sessenta e setenta do século passado, sob a designação de Educação Permanente e Educação ao Longo da Vida. As suas origens, contudo, em termos das principais ideias que agrega, são bem mais anteriores. Simóes encontra os princípios subjacentes à Educação Permanente em diversos momentos históricos, desde a Antiguidade Clássica, com a cidade ideal de Platão, onde se antevia que "todo o cidadão se pudesse educar, em todos os aspectos, ao longo de toda a vida” (1979, p. 200), até à literatura utópica dos séculos XV e XVI, com as obras, 'A utopia' de Thomas More, e a 'Cidade do Sol', de Tommaso Campanella.

Os conceitos de educação permanente e de educação ao longo da vida têm sido defendidos, desde os anos sessenta e setenta do século XX, no contexto da perspectiva humanista, a qual enfatiza a necessidade de se proporcionar uma distribuição mais equitativa das oportunidades educativas, garantindo não só que todos os espaços se tornem educativos, mas também que a educação se prolongue por toda a vida. Não têm sido, contudo, neste seguimento, que se fazem as actuais apostas educativas, muito mais enquadradas pela aprendizagem ao longo da vida, a qual passou a servir os interesses de orientaçóes políticas fortemente arredadas de preocupaçóes humanistas, no sentido em que instrumentalizam as pessoas, procurando prepará-las para se colocarem ao serviço da economia e não contribuir para desenvolver verdadeiros interesses de emancipação. Assim, de um conceito humanista, passámos a um conceito enquadrado pela lógica de mercado, e se a idade da reforma marca, geralmente, a saída do mercado de trabalho, os sistemas educativos, numa lógica de subserviência economicista, já não precisam de se preocupar com estes adultos!

Ora, nos últimos anos, e num movimento que se tem colocado nas antípodas da lógica de mercado, as universidades seniores têm vindo a afirmar-se de forma crescente, sendo procuradas por um público cada vez mais numeroso. Em Portugal, encontramos já na $1^{a}$ República, numa linha de educação popular, as chamadas universidades populares, numa tentativa de levar mais educação a todos os que estavam afastados da escola. Mas o movimento das Universidades Seniores que, de certo modo, tem o mesmo objectivo, ganha expressão, no caso português, sobretudo, durante a década de noventa do século XX. A nosso ver, ele decorre, pelo menos em parte, do envelhecimento populacional, fenómeno histórico recente, de abrangência mundial, que lança um novo desafio à organização social e que requer outro olhar sobre a adultez avançada, que não pode continuar a ser vista como uma antecipação da morte. É neste contexto que ganha pleno sentido o recente interesse científico pelo conceito de sabedoria.

\section{Sabedoria}

Embora a sabedoria se expresse de forma distinta consoante o tempo, a cultura ou as geraçóes, é um tema universal, com significado 'trans-histórico', 'transcultural' (Baltes, 
2004) e 'transdisciplinar' (Baltes, Glück \& Kunzmann, 2002). Não se trata, assim, de uma moda, ou de um novo conceito que tenha sido originado pelo actual desenvolvimento científico e tecnológico. Pelo contrário, o seu estudo remonta a tempos bem longínquos e tem interessado às "mais diversas tradiçóes culturais, religiosas e filosóficas" (Alves, 2007, p. 290), estando presente nos clássicos Gregos e Romanos, em escritos da Mesopotâmia e do Antigo Egipto (Baltes, 2004).

No mundo ocidental, a sabedoria não tem sido descurada pela religiáo (no Antigo e no Novo Testamento), mas também está presente na chamada sabedoria popular, destacando-se nos contos e nos provérbios, forma usual de transmissão oral de saberes. No caso da cultura oriental, a sabedoria tem assumido igualmente um papel de relevo ao longo dos séculos, quer no pensamento Budista e Taoista, quer nos escritos de Confúcio, e na espiritualidade Hinduísta (Alves, 2009; Baltes, 2004).

Apesar da relevância do tema, a sabedoria entrou tardiamente no campo científico, tendo passado a interessar à Psicologia, a partir dos anos oitenta do século XX, no âmbito do paradigma life span, surgindo como um ganho decorrente da idade. Desde então, a investigaçáo tem sido profícua, constituindo a obra de Sternberg "Wisdom: Its nature, origins and development”, publicada em 1990, um importante marco na abordagem empírica do constructo.

Nos estudos sobre a sabedoria é comum distinguirem-se dois grandes grupos: as teorias implícitas e as teorias explícitas. Enquanto as primeiras partem de abordagens populares, procurando saber de que forma são caracterizadas as pessoas sábias, as segundas pretendem aferir o nível de sabedoria dos sujeitos. No grupo das teorias explícitas, destacam-se as investigaçóes desenvolvidas no Max Plank Institute for Human Development and Education, por Baltes e colaboradores, as quais têm sido consideradas das mais sistemáticas realizadas sobre o tema.

No âmbito destas últimas teorias, tem-se verificado que alguns factores favorecem o desenvolvimento da sabedoria, nomeadamente, a idade cronológica, a experiência de um amplo leque de situaçôes e de condiçóes humanas, a prática do papel de tutor ou mentor e determinadas disposiçôes motivacionais, como, por exemplo, a generatividade (Marchand, 2005). Tal aponta para um substancial investimento pessoal e social, a nível de tempo, esforço e motivação para que a sabedoria se manifeste (Baltes \& Smith, 2008).

O desenvolvimento da sabedoria "é um processo extenso e intenso de aprendizagem e prática”, que requer um elevado grau de motivação e empenho, bem como condiçôes ambientais favoráveis. Segundo Baltes et al. (2002, p. 332), trata-se de um "processo complexo e multifacetado" que "envolve a orquestração de aspectos cognitivos, pessoais, sociais, interpessoais e espirituais", num pano de fundo de uma multiplicidade de vivências e experiências. Estes autores encaram a sabedoria como um sistema complexo e dinâmico de conhecimento de mestria, cuja avaliação resulta da ponderação dos seguintes cinco critérios (Baltes \& Smith, 2008; Baltes \& Staudinger, 1993, 2000):

1) Conhecimento elevado dos factos da vida - conjunto de conhecimentos sobre a natureza humana, nomeadamente, normas e interacçôes sociais, motivos, emoções, vulnerabilidades, acontecimentos significativos da vida e a sua ocorrência em função da idade, necessidades psicológicas da pessoa, entre outras;

2) Elevado conhecimento processual sobre problemas da vida - conhecimento de estratégias e conhecimentos, que permitam planificar acçóes e tomar decisóes, elevada capacidade de aconselhamento (e análise do outro) e elevada capacidade de analisar situaçôes e ponderar custos e benefícios; 
3) Elevado conhecimento contextual - capacidade de enquadrar os acontecimentos, olhálos de forma náo isolada, mas sim integrada. Situar os acontecimentos, quer na rede de relaçóes, quer temporalmente;

4) Elevado conhecimento sobre as diferenças de valores e prioridades - visão relativa da vida, capacidade de distinguir a sua própria visão das coisas e as dos outros, noção de que cada um tem as suas próprias percepçôes, capacidade de encarar possíveis soluçóes para uma mesma situação;

5) Elevado conhecimento sobre a imprevisibilidade da vida e habilidade para compreender e gerir a incerteza - capacidade de assumir que a vida é imprevisível, que as consequências das nossas acçóes nunca são totalmente previstas, que não existem certezas absolutas, que o futuro não pode ser totalmente controlado, mas que, ainda assim, a pessoa deve tomar decisóes e empenhar-se na acção.

As investigaçóes realizadas por Baltes e colaboradores recorrem à análise do discurso dos sujeitos, sobre diversas temáticas da vida, dando oportunidade para que demonstrem conhecimentos nos domínios da pragmática fundamental da vida, como o planeamento da vida, a gestão da vida e a revisáo da vida. Para avaliarem o conhecimento relacionado com a sabedoria, os autores utilizam o método "pensar alto" (thinking aloud), sobre dilemas complexos e mal estruturados (ou ambíguos), sendo as respostas gravadas, transcritas e classificadas tendo em conta os cinco critérios referidos.

\section{Objectivos e Metodologia}

O estudo teve como enquadramento teórico o modelo de Baltes e colaboradores, essencialmente por três razóes: 1) tem sido defendido por diversos autores como o que tem gerado as investigaçóes mais consistentes e profundas acerca do tema; 2) por ser enquadrado pela perspectiva life span e, nesse sentido, conceber o desenvolvimento humano como um processo extensível a toda a vida; 3 ) pela flexibilidade que a aplicação dos dilemas permite, no sentido em que estes são seleccionados em função da sua adequação aos participantes.

Sendo este estudo realizado no contexto da Educaçáo de Adultos, interessou-nos particularmente conhecer a sabedoria das pessoas reformadas, envolvidas, activamente, em processos de aprendizagem ao longo da vida e, por isso, optámos por o realizar numa universidade sénior, recaindo a nossa opção na universidade sénior da Figueira da Foz.

As pesquisas têm mostrado que a profissão é um importante factor preditivo da sabedoria, com um peso superior à inteligência e à personalidade. Por outro lado, também têm salientado que idosos que se encontram em situação de reforma e não exercem nenhuma actividade, sob a forma de voluntariado ou em regime de tempo parcial, dáo menos respostas de sabedoria do que idosos que ainda se encontram inseridos na vida profissional (Marchand, 2005). Assim, do nosso ponto de vista, é de grande importância estudar as pessoas que já saíram do mercado de trabalho por via da reforma. Para o efeito, formulámos os seguintes objectivos específicos, estruturantes da nossa investigação:

1) Verificar os níveis de conhecimento relacionado com a sabedoria dos participantes.

2) Analisar até que ponto os factores que a literatura aponta como sendo especialmente potenciadores do desenvolvimento da sabedoria, estiveram ou não presentes na vida destes adultos de idade avançada. 
3) Relacionar os factores potencialmente promotores de sabedoria com as suas respostas de sabedoria, no sentido de se poder identificar o que está subjacente a uma reforma activa, educativa e sábia.

4) Identificar factores relevantes da história de vida dos sujeitos que possam ajudar a compreender o envolvimento elevado em actividades de aprendizagem, sobretudo de carácter não formal, em etapas avançadas da vida.

A nível metodológico, tendo em conta os nossos objectivos, e numa visão que se pretende simultaneamente crítica, construtiva e humanista, a nossa opção recaiu sobre a investigação qualitativa. Utilizámos, para a recolha de dados, uma entrevista semi-estruturada e um dilema de revisão de vida. Participaram no estudo seis seniores, de ambos os sexos, com idades compreendidas entre os 56 e os 70 anos e com habilitaçóes escolares entre o ensino secundário e a licenciatura.

\section{Apresentaçáo dos Resultados}

As entrevistas, submetidas a análise de conteúdo, foram objecto de uma leitura inicial, desenvolvida em função dos blocos temáticos do guião. Esta leitura, vertical, permitiu a reconstrução da história de vida dos participantes. Em segundo lugar, foram objecto de uma leitura horizontal, possibilitando a comparaçáo dos relatos, detectando-se semelhanças, pontos de contacto, mas igualmente, contradições e oposiçóes, que passamos de seguida a apresentar.

Relativamente aos percursos de vida, verificamos que os aspectos de âmbito pessoal, escolar e profissional, aparecem entrelaçados, constituindo uma dinâmica própria. Os percursos de vida mostram-se ricos e diversificados, com mudanças a diferentes níveis e desafios diversos. Em todos os discursos, a família aparece como um elemento central, ora impulsionador, ora restritivo da acção, nomeadamente no contexto escolar e no contexto profissional. A nível profissional, os percursos que identificámos são bastante ricos e plenos de desafios e mudanças. Em todos os protocolos, a profissão surge como elemento crucial no desenvolvimento da identidade pessoal e social, nunca sendo encarada apenas como meio de sobrevivência financeira. De referir ainda que a profissão é escolhida e decorre da vocação, do interesse próprio e da influência familiar.

A reforma é um tema central da entrevista, interessando não só perceber a avaliação que é feita da "vida de reformado", mas perceber, igualmente, se foi ou não planeada e como decorreu a transição da vida activa para a situação de reforma. O tema surge na entrevista, adicionalmente, como um elemento potenciador da reflexão acerca do envelhecer e do envelhecimento, já que a reforma marca não só a perda de determinados papéis sociais, como também representa e simboliza a entrada na velhice.

No que diz respeito ao planeamento da reforma, as respostas não são unânimes, surgindo casos em que ele é feito desde cedo, com um forte investimento no envelhecimento activo e saudável, assim como se verificaram outros em que esse planeamento não existiu. Ainda assim, os relatos dos participantes permitem-nos descrever uma reforma vivida de forma activa, com rotinas diárias e semanais, que permitem assemelhar os ritmos de vida, aos da vida activa. Esses mesmos relatos revelam uma adultez avançada que contradiz todos os estereótipos. Saudáveis, úteis para os seus e para outros, sujeitos activos e empenhados em 
processos de aprendizagem e felizes, retratam a reforma como um tempo para si próprios, como uma oportunidade para ocupar o tempo da forma que mais gostam.

A avaliação, os olhares e sentimentos relativamente à universidade sénior, assumem uma grande importância, tendo-se verificado que todos os participantes fazem uma avaliação muito positiva desta instituição. As aulas e as actividades extracurriculares, nomeadamente as visitas de estudo, as exposiçóes e lançamento de livros, são valorizados e entendidos como tendo um duplo objectivo: a aprendizagem e o convívio.

No que diz respeito ao papel de mentor, aqui operacionalizado através do aconselhamento, surge no conjunto dos protocolos, quer em contexto profissional (inerente ou não à profissão) quer em contexto pessoal e é caracterizado mais como disponibilidade e abertura em relação ao outro, do que imposição.

Relativamente ao dilema utilizado, optámos por criar um dilema de revisão de vida, que testámos previamente. Depois de transcritas as respostas, procedeu-se à cotação, utilizandose uma escala de sete pontos. A cotaçáo foi realizada pelas autoras deste trabalho e por mais uma investigadora bastante familiarizada, nos seus estudos, com o modelo de Baltes e colaboradores e a perspectiva do desenvolvimento co-extensivo à duração da vida. Nos casos de algum desacordo, foram revistas as respostas dos seniores e procurou-se chegar a um acordo ulterior quanto à pontuação.

Quadro 1. Resultados globais do dilema de revisão de vida, por participante e por critério

\begin{tabular}{lcccccc}
\cline { 2 - 7 } & B & C & D & E & F & G \\
\hline Conhecimento Factual & 6 & 5 & 5 & 5 & 6 & 5 \\
\hline Conhecimento Processual & 5 & 4 & 4 & 4 & 5 & $4+$ \\
\hline Conhecimento Contextual & 5 & $4+$ & 4 & 5 & 6 & 4 \\
\hline Conhecimento Relativista & 5 & $5+$ & 5 & 4 & 5 & 5 \\
\hline Conhecimento sobre a Imprevisibilidade & 5 & 5 & 5 & - & 6 & 4 \\
\hline Cotaçáo Global & 5 & 5 & $4+$ & $4+$ & $5+$ & $4+$ \\
\hline
\end{tabular}

Verificamos que nos seis participantes analisados, três obtiveram a classificação de 4+, dois obtiveram a classificaçáo de 5 e um obteve $5+$, o que significa que todos eles mostraram ter, pelo menos, um nível médio de conhecimento relacionado com a sabedoria. Por outro lado, e indo de encontro à raridade da sabedoria, nenhum dos participantes foi classificado como profundamente sábio, embora um deles se tivesse aproximado deste nível.

\section{Discussáo dos Resultados}

Embora a maior parte dos autores levante a hipótese do conhecimento relacionado com a sabedoria ser uma característica que decorre da experiência de vida, e que, por isso, se encontra sobretudo nas idades mais avançadas do ciclo de vida, as pesquisas empíricas não o têm evidenciado de forma consistente. Segundo Baltes e colaboradores, o desenvolvimento da sabedoria exige um grande investimento pessoal e social (Baltes \& Smith, 2008), resultando da conjugação de diversos aspectos, i.e., para que sejam alcançados elevados níveis de desempenho, os indivíduos e as sociedades têm de investir uma quantidade razoável de 
esforço! Lembramos Baltes e Staudinger (2000), que encaram a sabedoria como produto cultural e colectivo, no qual os indivíduos participam e do qual são portadores.

Tềm sido considerados como factores importantes no desenvolvimento da sabedoria, a vivência de experiências ricas e diversificadas, bem como a prática dos papéis de mentor e de tutor e determinadas disposiçóes motivacionais, como o interesse pela compreensão dos outros. A pesquisa tem ainda mostrado que a profissão é um dos mais importantes factores preditivos da sabedoria. O treino e a prática profissional, destacando-se as profissóes de ajuda, têm sido indicados como uma das mais importantes influências para o desenvolvimento da sabedoria, pelo que, estar na condição de reforma, poderá ser um factor prejudicial a nível do desenvolvimento da sabedoria.

Outro dos factores, que tem sido considerado como potenciador do conhecimento relacionado com a sabedoria, é a interacção com pessoas significativas, o que, após a saída do mercado de trabalho, tende a diminuir. Todavia, no caso dos nossos participantes, tal não parece ter acontecido, uma vez que os seniores que entrevistámos permanecem envolvidos em actividades diversas, as quais revelaram potenciar as relaçóes interpessoais significativas.

Consideramos que estes resultados apontam para uma suposta influência positiva dos níveis médios altos de sabedoria, na transição para a reforma, em condiçóes em que essa transição possa estar ameaçada. Recordamos que Baltes e colaboradores, como resultado das suas investigaçóes, desenvolveram um modelo psicológico de envelhecimento bem sucedido, baseado em ganhos e perdas, que denominaram Optimização Selectiva com Compensação (SOC), considerando o desempenho sábio, como um exemplo deste mecanismo.

A partir das entrevistas, podemos retratar a reforma, não como tempo de inactividade ou isolamento, mas precisamente o inverso: o quotidiano destes reformados é caracterizado pela ocupação em diversas actividades, pela definição de tarefas, de horários e de objectivos, ou seja, é organizado por uma estrutura de vida em que a auto-determinação e auto-regulação se revelam elevadas. A reforma é considerada como uma oportunidade para desenvolver actividades diversificadas, tais como a frequência da universidade sénior, a participação em actividades de voluntariado, a dedicação à família e aos amigos, a realização de actividades desportivas, de lazer e culturais. Sobressaiu também das entrevistas que a reforma é considerada como oportunidade para adoptar ou reforçar um estilo de vida saudável, sendo referidos, de forma bastante consistente, os cuidados médicos, o desporto e a alimentação.

As palavras de Simóes (2006) adequam-se perfeitamente ao que encontrámos neste estudo: "da ideia do indivíduo passivo, sentado no banco do jardim, a ver as pessoas passar, vai-se chegando a um cidadão dinâmico, desejoso de participar na vida da comunidade", cujas condições de vida lhe permitem "maior confiança no futuro e estimulam-no a aproveitar, de maneira pessoalmente mais enriquecedora, os anos mais longos da aposentação" (p. 155).

Por outro lado, em geral, também se destaca quer nas entrevistas, quer nos dilemas, um grande autoconhecimento e capacidade de reflexão e auto-reflexão. Lembramos que, na perspectiva de Ardelt (2004), a auto-reflexáo ajuda a pessoa a perceber, de forma humilde, os seus limites. E, nesse sentido, as pessoas sábias estão, também, do ponto de vista afectivo, mais preocupadas com assuntos universais, do que simplesmente com o seu bem-estar. Vimos este retrato de certa forma reflectido na nossa amostra, uma vez que, nas diversas entrevistas, foi sobressaindo uma preocupação relativamente ao outro, emergindo interesses altruístas. Para Ardelt, este aspecto está relacionado com a satisfação com a vida e com a serenidade, na medida em que permite à pessoa aceitar as limitaçóes da vida, nomeadamente, a nível das alteraçôes físicas e a morte. Nas entrevistas notámos 
também que as alteraçóes físicas tendem a ser encaradas com alguma naturalidade. Para Macdonald (1981, cit. por Alves, 2009, p. 112) “as pessoas sábias atingem uma compreensão mais apurada de si próprias, elas estão atentas às suas forças e fraquezas e desenvolvem estratégias capazes de as controlar e promover". Pensamos encontrar aqui, na capacidade de adaptação às mudanças biológicas inerentes ao envelhecimento, à capacidade de viver com as contradiçóes e à adaptaçáo na mudança, algumas das características do pensamento dialéctico, de que falámos anteriormente.

E, especificamente, no que diz respeito ao fenómeno educativo, os seniores entrevistados são cidadãos que permanecem envolvidos em processos de aprendizagem intencionais $\mathrm{e}$ que reconhecem, em si próprios, capacidade para continuar a aprender. A frequência da universidade sénior não é caracterizada como um mero momento de lazer ou de convívio, mas, pelo contrário, surge com o objectivo bem definido de aprender. Esta vertente é bem acentuada e valorizada, surgindo em todas as entrevistas. Aprender informática, inglês, história ou fotografia digital, não é para estes seniores um mero passatempo, mas uma necessidade e um objectivo! As próprias visitas de estudo são tanto mais valorizadas quanto mais propiciam novas aprendizagens. Parece pois que o conceito de si como educandos ao longo da vida está bem arreigado nos seniores investigados.

A aposentação, uma das transiçôes mais importantes do ciclo de vida, não pode ser ignorada pela educação, que, antes de mais, deve "empenhar-se em destruir mitos que em torno dela se geram" (Simóes, 2006, p. 100), porque as investigaçóes têm mostrado que "a maioria das pessoas se adapta, satisfatoriamente, à aposentação e se sente feliz na mesma. Para muitos, pode até representar melhorias em vários aspectos da sua vida - na saúde física e mental, na prestação de cuidados a familiares, no envolvimento em favor da comunidade" (p. 100). Ora, o nosso estudo reforçou, precisamente, o que acabou de ser afirmado.

Em jeito de conclusão, podemos dizer que os aspectos que geralmente se associam à génese da sabedoria, no quadro das investigaçôes de Baltes e colaboradores, estiveram presentes nos protocolos referidos, o que, no nosso entender, confirma a importância destes aspectos no desenvolvimento do comportamento sapiencial.

Pensamos que envolver as pessoas em aprendizagens significativas e deliberadas, pode contribuir para melhorar a sua qualidade de vida, manter o seu nível de autonomia e contribuir para que se sintam valorizadas e continuem a dar contributos para a sociedade. Permitir que os idosos se dediquem ao que gostam, representa uma mais-valia para todos: para os idosos, mas também para a sociedade em geral e para os sistemas de ensino em particular.

Possa a sociedade estar preparada, quer para aproveitar os recursos dos adultos de idade avançada, que pela sua experiência podem ser óptimos educadores, quer para voltar a respeitar os princípios da educação permanente, concretizando os seus ideais igualmente na etapa da idade adulta avançada. 


\section{Referências Bibliográficas}

Alves, P. J. P. (2007). A sabedoria: Construção de uma nova escala. Psicologia, Educação e Cultura, XI (2), $289-306$.

Alves, P J. P. (2009). Sabedoria: Definição, multidimensionalidade e avaliação. Dissertação de Doutoramento não publicada. Coimbra: Faculdade de Psicologia e de Ciências da Educação.

Amado, J. (2009). Introdução à investigação qualitativa em educação. Relatório de disciplina apresentado nas Provas de Agregação não publicado. Coimbra: Faculdade de Psicologia e de Ciências da Educação.

Ardelt, M. (2004). Wisdom as expert knowledge system: critical review of a contemporary operationalization of an ancient concept. Human Development, 47 (5), 257-285.

Baltes, P.B. (2004). Wisdom as an orchestration of mind and virtue. Book in preparation. Acedido a 05/10/2009 em: <www.baltes-paul.de/overview.htm>

Baltes, P. B., Glück, J., \& Kunzmann, U. (2002). Wisdom: Its structure and function in regulating successful life span development. In. C. R. Snyder \& S. J. Lopez (Eds.), Handbook of Positive Psychology (pp. 327-347). New York: Oxford University Press.

Baltes, P. B., \& Smith, J. (2008). The fascination of wisdom: Its nature, ontogeny and function. Perspectives on Psychological Science, 3 (1), 56-64.

Baltes, P. B., \& Saudinger (1993). The search of psychology of wisdom. Current Directions in Psychological Science, 2 (3), 75-80. Retirado da base de dados EBESCO, a 17 de Junho de 2009.

Baltes, P. B. \& Staudinger (2000). A metaheuristic (pragmatic) to orchestrate mind and virtue toward excellence. American Psychologist, 55 (1), 122-136. Acedido a 18/10/2009 em:http://education.ucsb.edu/janeconoley/ ed197/documents/balteswisdom.pdf>

Brookfield, S. D. (1995). Developing critical thinkers: Challenging adults to explore alternative ways of thinking and acting ( $3^{a}$ ed.). Milton Keynes: Open University Press.

Freire, P. (2008). Pedagogia da autonomia: Saberes necessários à prática educativa (37a ed.). São Paulo: Editora Paz e Terra.

Gonçalves, C. D. (2010). Sabedoria e Educação. Um estudo com adultos da universidade sénior. Tese de Mestrado não publicada. Coimbra: Faculdade de Psicologia e de Ciências da Educaçáo.

Loevinger, J. (1987). Ego development: Conceptions and theories (5a ed.). San Francisco: Jossey-Bass Publishers.

Marchand, H. (2005). A idade da sabedoria: Maturidade e envelhecimento. Porto: Âmbar.

Mezirow, J. (1991). Transformative dimensions of adult learning. San Francisco: Jossey-Bass Publisher.

Mezirow, J. (2000). Learning to think like an adult: Core concepts of transformational theory. In J. Mezirow \& Associates, Learning as transformation: Critical perspectives on a theory in progress (pp. 3-33). San Francisco: Jossey-Bass Publishers.

Nazareth, J. M. (2009). Crescer e envelhecer: Constrangimentos e oportunidades do envelhecimento demográfico. Lisboa: Editorial Presença.

Oliveira, A. L. (2002). O processo de individuação e as teorias do desenvolvimento da identidade e do eu: Até onde o olhar alcança. Psychologica, 30, 267-283.

Oliveira, A. L. (2007). Desenvolvimento do pensamento reflexivo e educação de adultos: Uma revisão de modelos teóricos. In A. C. Fonseca, M. J. Seabra-Santos \& M. F. Gaspar (Eds.), Psicologia e educação: Novos e velhos temas (pp. 217-246). Coimbra: Ediçôes Almedina.

Simôes, A. (1979). Educação permanente e formação de professores. Tese de doutoramento em Ciências da Educação. Coimbra: Faculdade de Psicologia e de Ciências da Educação.

Simóes, A. (1989). O que é educar? Acerca do constitutivo formal do conceito. Revista Portuguesa de Pedagogia, 23, 3-20.

Simóes, A. (1990). Alguns mitos respeitantes ao idoso. Revista Portuguesa de Pedagogia. 24, 109-121.

Simóes, A. (2006). A nova velhice. Um novo público a educar. Porto: Âmbar.

Simóes, A. (2007). O que é a educação? In A. Fonseca, M. Seabra-Santos, M. Fonseca (Eds.), Psicologia e Educaçâo: Novos e velhos temas (pp. 31-52). Coimbra: Almedina.

Simões, A., Lima, M. P., Vieira, C. M. C., Oliveira, A. L., Alcoforado, J. L., \& Ferreira, J. A. (2009). O sentido da vida: Contexto ideológico e abordagem empírica. Psychologica, 51, 101-130. 

Série Documentos

Imprensa da Universidade de Coimbra

Coimbra University Press

2011

- U

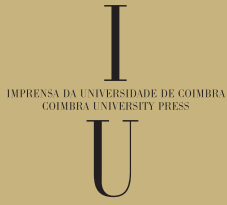

